\title{
Antioxidant activities of ethanolic extract of Annona muricata leaves against different pro-oxidant induced lipid peroxidation in rat brain and liver
}

\begin{abstract}
Background and objective: Over the years, numerous works have documented the antioxidant potency of Annona muricata as well as it medicinal actions against myriad of ailments. However, there is still vague information as regard its antioxidant ability against diverse types of prooxidants. This work is carried out to deduce the antioxidant capacity of ethanol extract of A. muricata against different pro-oxidants in the cerebral and hepatic tissues of rats in in vitro models.

Methods: Fresh leaves of $A$. muricata were washed, air-dried, pulverized and extracted with ethanol. Rats were euthanized and the tissues (brain and liver) were removed and homogenized in 50mM Tris- $\mathrm{HCl}, \mathrm{pH} 7.4$. The homogenates were centrifuged for $10 \mathrm{~min}$ at 4000rpm to obtain a low-speed supernatant that was used for TBARS assay in the presence of extract and five different pro-oxidants; Iron (II) sulphate, hydrogen peroxide, 3-Nitropropionic acid, Sodium nitroprusside and quinolinic acid.

Results: The results reveal that $A$. muricata extract displayed strong potency against lipid peroxidation in both the brain and liver tissue homogenates by inhibiting the production of thiobarbituric acid reactive substances irrespective of the prooxidant used. This polytropic antioxidant ability of $A$. muricata extract could be linked to its high polyphenolic content which confers on it, a strong redox property as well as a hydrogen donating power. This research therefore paves way for further investigation on the therapeutic actions of $A$. muricata in lipid peroxidation mediated ailments and diseases.
\end{abstract}

Keywords: A. muricata, antioxidant, ethanolic extract, lipid peroxidation, prooxidants

\author{
Volume 9 Issue 2 - 202I
}

\author{
Ebenezer Morayo Ale,' Adesola Oluwaseun \\ Adeleye, ${ }^{2}$ Olanrewaju Roland Akinseye, ${ }^{3}$ \\ Ebenezer Kayode Toluwalase ${ }^{4}$ \\ 'Department of Biochemistry, Faculty of Pure and Applied \\ Sciences, Federal University Wukari, Nigeria \\ ${ }^{2}$ Department of Chemical Sciences, Olusegun Agagu University \\ of Science and Technology, Nigeria \\ ${ }^{3}$ Nigeria Institute for Trypanosomiasis and Onchocerciasis \\ Research, lbadan \\ ${ }^{4}$ Waterspring International School, Nigeria
}

Correspondence: Ebenezer Morayo Ale, Department of Biochemistry, Faculty of Pure and Applied Sciences, Federal University Wukari, Federal University Wukari, P.M.B. 1020, Wukari, Taraba State, Nigeria, Tel +2347038I59057, Email ebenezerale@gmail.com; alebenezer@fuwukari.edu.ng

Received: March 26, 2021 | Published: April 05, 2021

\section{Introduction}

Annona muricata belongs to the family Annonaceae, which is rampant in the tropical and subtropical regions of the globe such as North America, Africa, Thailand and Asia. ${ }^{1}$ Several pharmacological activities such as anti-inflammation, anti-diabetes, hepatoprotective and countless other benefits have been attributed to the extracts from the plant. ${ }^{2-7}$ The phytoconstituents residing in the plant exhibit disease preventive properties, though they are not essential nutrients to human health. The plant is a domicile of essential bioactive compounds such as annonaceous acetogenins, polyphenols, tannin and alkaloids. ${ }^{8}$ Various parts of the plant including the bark, fruit and seed are said to possess medicinal properties and its bark decoction, root, seed and leaf are vastly used in traditional medicine. ${ }^{9}$

Lipid peroxidation often involves oxidative damage by free radical assault on the membrane lipids. Lipid peroxidation plays crucial roles in the pathogenesis of numerous diseases such as diabetes, Parkinson disease, silicosis and cancer. Radical oxidation involves the attack on unsaturated fatty acids with multiple bonds by reactive oxygen species (ROS), abstraction of hydrogen atom and eventual generation of lipids radicals which results in the destruction of membrane lipids. Oxidative stress by ROS usually involves a chain of reactions which leads to damage of cell constituents such as proteins, lipid and nucleic acids. $^{10}$

Consequent to their preventive role against free radical oxidation which results in emergence of several diseases such as cancer, cardiovascular problems and neurodegenerative diseases such as
Parkinson and Alzheimer disease, natural antioxidants from plants have become a subject of attraction and interest in combating and treating diseases, ${ }^{11}$ Several experimental guided researches have documented the antioxidant activities of $A$. muricata, ${ }^{12,13}$ but there is dearth of information as regard the antioxidant potential of the plant on several prooxidants. This research is therefore undertaken to investigate the antioxidant potential of ethanol extract of $A$. muricata against different prooxidants in rat cerebral and hepatic tissues.

\section{Methods}

\section{Chemicals}

Thiobarbituric acid (TBA) and Tris- $\mathrm{HCl}$ were obtained from Sigma Chemical Co., St. Louis, MO, USA. Other chemicals used were obtained from certified suppliers.

\section{Animals}

15 male wistar rats with weight range of $200-250 \mathrm{~g}$ were kept at room temperature under $12 \mathrm{~h}$ light/dark cycle with access to water and food. Animals were housed and handled in adherence to Committee on Care and Use of Experimental Animal Resources guideline.

\section{Extract preparation}

Fresh leaves of $A$. muricata were washed with water and dried under shade at room temperature. The dried leaves were grinded with mechanical grinder and $200 \mathrm{~g}$ of the pulverized leaves was macerated in $600 \mathrm{ml}$ absolute ethanol for three days. The extract was then filtered, concentrated in a rotary evaporator and stored at $4^{\circ} \mathrm{C}$ for assays. 


\section{Preparation of tissue homogenate}

Animals were anesthetised with ether, decapitated and the brains and livers removed. The tissues were rinsed thoroughly with cold $50 \mathrm{mM}$ Tris- $\mathrm{HCl}$ buffer to ensure that they are free from blood stain and immediately homogenized in cold with $50 \mathrm{mM}$ Tris-HCl buffer $(1: 10 \mathrm{w} / \mathrm{v}), \mathrm{pH} 7.4$. The homogenate was centrifuged at $4000 \mathrm{rpm}$ for 10 min and the supernatant was decanted and used for assays.

\section{Lipid peroxidation assay}

Lipid peroxidation in the tissue was carried out by quantifying TBARS (thiobarbituric acid reactive species) using the method according to Ohkawa et al..$^{14} 100 \mu$ l of the supernatant was incubated with extract (of concentrations between $0-100 \mathrm{mg} / \mathrm{ml}$ ) for 1 hour at $37^{\circ} \mathrm{C}$ in the presence of pro-oxidants $\left[10 \mu \mathrm{M} \mathrm{FeSO}_{4}\right.$ or $1 \mathrm{mM} \mathrm{H}_{2} \mathrm{O}_{2}$ or $2 \mathrm{mM}$ quinolinic acid (QA) or 2mM 3-nitropropionic acid (3-NPA) or $5 \mu \mathrm{M}$ sodium nitroprusside (SNP)]. The reaction was carried out in $50 \mathrm{mM}$ Tris-HCl buffer (pH 7.4). $200 \mu 1$ of $8.1 \%$ SDS (Sodium Dodecyl Sulphate), $500 \mu 1$ of acetate buffer $\mathrm{pH} 3.4$, and $500 \mu 1$ of $0.8 \%$ TBA were added to develop the colour reaction. The reaction system was then incubated for 30 minutes at $100^{\circ} \mathrm{C}$ and TBARS was read at $532 \mathrm{~nm}$ in UV-visible spectrophotometer.

\section{Statistical analysis}

Data were analyzed using ANOVA and Duncan's multiple range tests where necessary and all values were expressed as mean \pm SEM. * and \# represent significant difference from control at $\mathrm{p}<0.05$.

\section{Results}

The effects of the ethanolic extract of A. muricata on lipid peroxidation induced by the five prooxidants used are presented in figure 1 to 5 . $\mathrm{FeSO}_{4}, \mathrm{H}_{2} \mathrm{O}_{2}, 3-\mathrm{NPA}$ and SNP provoked peroxidation in both the liver and brain lipids while QA, a neurotoxin induced peroxidation in the brain as observed from the high level of thiobarbituric acid reactive substances formed in the reaction medium. Interestingly, in all cases, the extract profoundly reversed and inhibited the peroxidation in concentration dependent manner in both the cerebral and hepatic tissues and this inhibitory effect was statistically significant $(\mathrm{P}<0.05)$ compared to the control.

\section{Discussion}

Free radicals emanate from both endogenous and exogenous sources. The hydroxyl radical, $\mathrm{OH} \bullet$ for instance, which is considered to be a major partaker in oxidative damage is largely generated endogenously by reaction of $\mathrm{H}_{2} \mathrm{O}_{2}$ with transition metal ions, especially iron..$^{15-20}$ Also, superoxide ion $\left(\mathrm{O}_{2} \bullet\right)$ is a toxic radical which liberates the iron required for Fenton reaction from iron-containing proteins. ${ }^{21,22}$ Drugs, transition metals and pesticides are examples of exogenous sources of prooxidants from which free radical are generated. ${ }^{23}$ In similar fashion to free radicals, antioxidants such as reduced glutathione (GSH) can be synthesized within the living cells, while some, like vitamin $\mathrm{C}$ and carotenoids can be exogenously supplied into the system. ${ }^{24,25}$

Lipid peroxidation provides a means of identifying antioxidants such as vitamins and polyphenols in plants as well as elucidating their mechanisms of action in several models such as rat hepatic homogenate. ${ }^{26}$ Considering the fact that membrane fluidity is made possible by the presence of polyunsaturated fatty acids in the phospholipid bilayers, lipid peroxidation is highly destructive to the functioning of cell and its survival. Lipid peroxidation reduces the fluidity of the membrane and alters its unique properties and integrity.
It causes assaults to the plasma membrane of the hepatocytes and this leads to leakage of large molecules such as enzymes from the cell. ${ }^{27}$

Antioxidants carry out their function during biological processes including inflammation by balancing and stabilizing generated free radicals. ${ }^{28,29}$ Antioxidants adopt different mechanisms in achieving their defence function. They impede the reaction of free radicals with proteins by sequestering them with transition metals, they make provision for free radical scavenging molecules as well as specific mechanisms for repairing DNA damage induced by ROS. ${ }^{30}$

Worthy of note is the fact that A. muricata extract contains polyphenols, flavonoids, steroids, glycosides, alkaloids and tannins. ${ }^{8}$ Many in vitro studies suggest that phenolic compounds, including flavonoids, have considerable antioxidant activity. ${ }^{31,32}$ Studies also revealed that there is a close link between phenolic content and free radical scavenging property. Phenolic compounds are strong reducing agents as well as hydrogen donors due to their redox property and this accounts for their antioxidant action. ${ }^{33,34}$

$\mathrm{Fe}^{2+}$ is one of the most potent pro-oxidant in both brain and liver and its mechanism of lipid peroxidation induction involves the reaction of $\mathrm{Fe}^{2+}$ with oxidants (In most cases, $\mathrm{O}_{2}$ or $\mathrm{H}_{2} \mathrm{O}_{2}$ ) which results in ROS production. ${ }^{35}$ The Fenton reaction (reaction between $\mathrm{Fe}^{2+}$ and $\mathrm{H}_{2} \mathrm{O}_{2}$ ) is known to yield large amounts of the very reactive $\mathrm{OH}$ radical in initiating lipid peroxidation. ${ }^{36}$ As shown in Figure 1, $\mathrm{Fe}^{2+}$ treatment provoked an increased production of thiobarbituric acid reactive substances due to peroxidation of the brain and liver lipids, but $A$. muricata extract profoundly inhibited the peroxidation caused by $\mathrm{Fe}^{2+}$ and this effect was significantly different $(\mathrm{p}<0.05)$ from the control.

Figure I Antioxidant activity of A. muricata against $\mathrm{Fe}^{2+}$-induced lipid

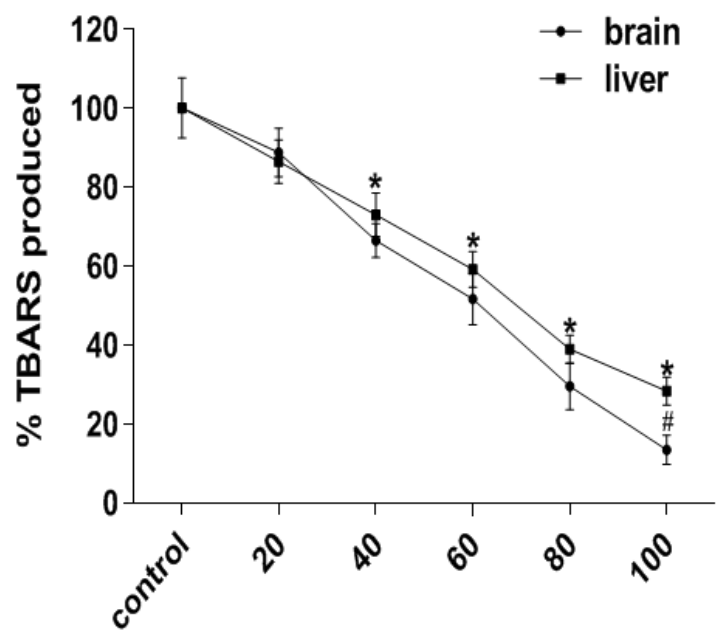

peroxidation in rat brain and liver homogenates. Data are presented as mean \pm SEM of three independent experiments. * and \# Represent significant difference from control at $\mathrm{p}<0.05$.

Moreover, the role of $\mathrm{H}_{2} \mathrm{O}_{2}$ in the formation of free radicals which leads to tissue injury cannot be overemphasised. The mechanism of $\mathrm{H}_{2} \mathrm{O}_{2}$-induced peroxidation is by Fenton reaction with ferrous salt thus generating hydroxyl radical. Hence, $\mathrm{H}_{2} \mathrm{O}_{2}$ can be regarded as an effective oxidant of a large variety of biomolecules including lipids. ${ }^{37,38}$ Figure 2 reveals that $\mathrm{H}_{2} \mathrm{O}_{2}$ constituted a marked increase in lipid peroxidation in cerebral and hepatic tissues of rat. Conversely, A. muricata extract effectively inhibited the peroxidation process in a dose dependent manner. 
Figure 2 Antioxidant activity of $A$. muricata against $\mathrm{H}_{2} \mathrm{O}_{2}$-induced lipid

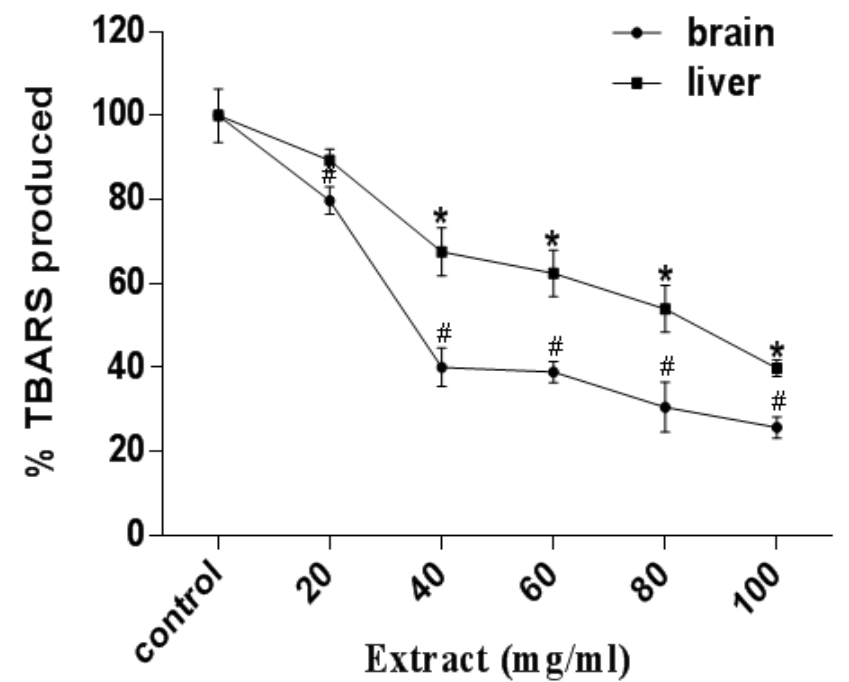

peroxidation in rat brain and liver homogenates. Data are presented as mean \pm SEM of three independent experiments. $*$ and \# Represent significant difference from control at $\mathrm{p}<0.05$.

Moreso, the mechanism by which 3NPA induces peroxidation is by inhibiting succinate dehydrogenase (SDH). SDH which is the complex II in the mitochondria is the enzyme responsible for the blockage of electron transport during oxidative phosphorylation. The inhibition of SDH leads to a reduction in ATP levels and as well induces oxidative stress ${ }^{39}$ with a concomitant elevation of oxygen flux in the mitochondria, which finally results in the production of ROS and RNS..$^{40} 3$-NPA caused an increase in peroxidation of lipids in the rat brain and liver homogenates, but the extract treatment caused a significant $(\mathrm{p}<0.05)$ inhibition of thiobarbituric acid reactive substances formation in both tissues (figure 3 ).

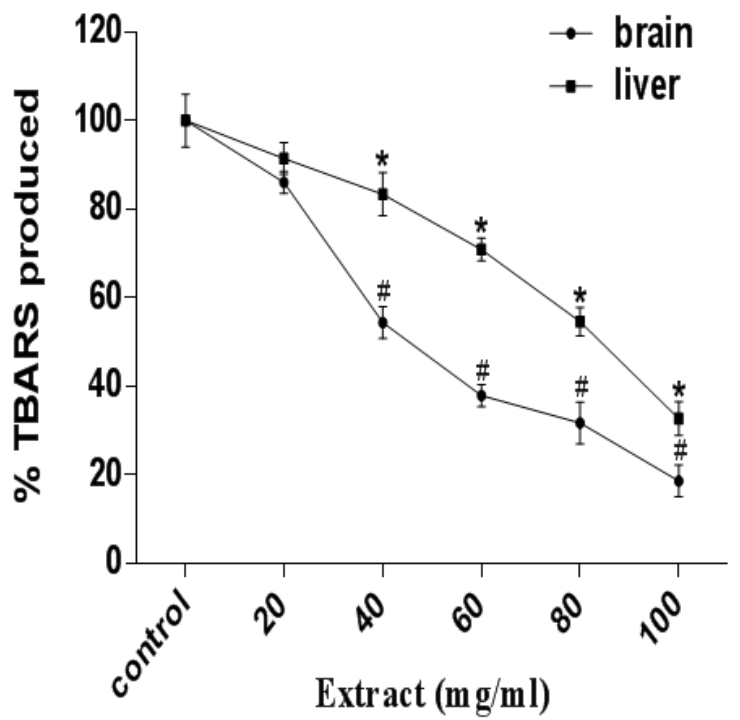

Figure 3 Antioxidant activity of A. muricata against 3-NPA-induced lipid peroxidation in rat brain and liver homogenates. Data are presented as mean \pm SEM of three independent experiments. * and \# Represent significant difference from control at $\mathrm{p}<0.05$.

Furthermore, sodium nitroprusside (SNP), an antihypertensive drug induces lipid peroxidation by liberating nitric oxide and cyanide
(NO) ${ }^{41}$ NO contributes to physiological disorders which lead to stroke and other degenerative diseases. ${ }^{42}$ As displayed in figure 4, SNP provoked an increased level of lipid peroxidation in rat hepatic and cerebral tissues, but the extract counteracted lipid peroxidation in concentration dependent manner as observed from the momentous decrease in thiobarbituric acid reactive substances formation in both tissue homogenates.

Figure 4 Antioxidant activity of A. muricata against SNP-induced lipid

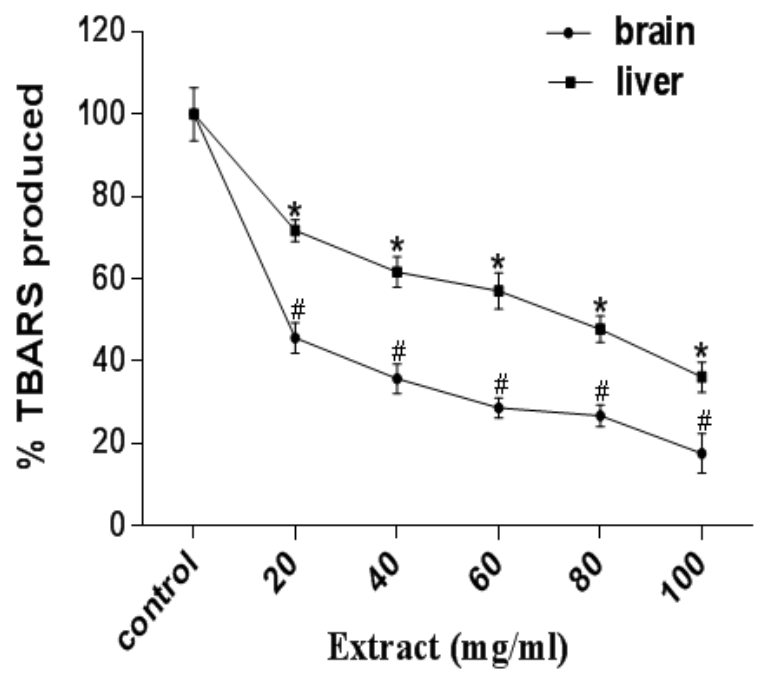

peroxidation in rat brain and liver homogenates. Data are presented as mean \pm SEM of three independent experiments. * and \# Represent significant difference from control at $p<0.05$

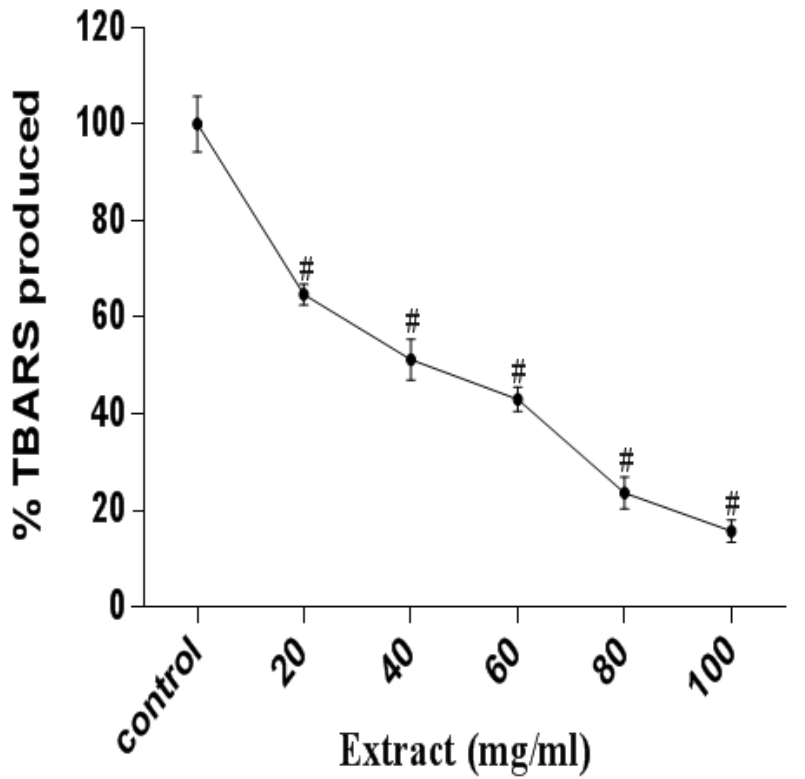

Figure 5 Antioxidant activity of $A$. muricata against QA-induced lipid peroxidation in rat brain homogenate. Data are presented as mean \pm SEM of three independent experiments. \# Represent significant difference from control at $\mathrm{p}<0.05$

In addition, quinolinic acid is a neurotoxin and an endogenous metabolite of tryptophan in kynurenine pathway. The mechanism of Quinolinic acid-induced peroxidation is mediated by overactivation of glutamate receptors. ${ }^{43}$ It has been proposed that quinolinate-induced lipid peroxidation in the rat brain is dependent on iron concentrations. ${ }^{44}$ 
Figure 5 shows that quinolinic acid caused a marked increase in the formation of aldehydic adducts of lipid peroxidation in the cerebral tissue homogenate, but extract treatment abolished the harmful effect of quinolinic acid. To this effect, the results herein shows that the ethanol extract of $A$. muricata has a substantial antioxidant action irrespective of the prooxidant used.

Very important is the fact that extracts of A. muricata exhibit free radical scavenging, metal reducing as well as lipid substrate oxidation inhibitory activities. ${ }^{45}$ Numerous antioxidant compounds in A. muricata have been reported to be lipophilic and carry out their actions by donating hydrogen. ${ }^{12}$ Knowing fully well that there is a strong link between antioxidant activity of $A$. muricata extracts and their phenolic content, ${ }^{46}$ this may account for their redox potentials, which equip them with the ability to function as hydrogen donors as well as reducing agents. Due to its high polyphenols content, $A$. muricata also has the ability to block oxidation and activates other antioxidants. ${ }^{47}$ Consequently, they are able to neutralize free radicals due to the presence and action of hydroxyl groups of phenolic compounds. ${ }^{33,34,48}$ It is therefore rational to suggest that these reported polytropic mechanisms of A. muricata action could be responsible for its antioxidant capacity against all the prooxidants employed herein.

\section{Conclusion}

The results of this research work reveal that ethanolic extract of A. muricata vastly inhibited lipid peroxidation induced by all the prooxidants in both the cerebral and hepatic tissues. Annona muricata could therefore be a promising candidate in developing natural antioxidant source.

\section{Acknowledgments}

We appreciate the concerted efforts and contribution of all authors toward the success of this research work, as there was no external sponsorship for the project.

\section{Conflicts of interest}

Authors declare that there is no conflict of interest.

\section{References}

1. Moghadamtousi SZ, Fadaeinasab M, Nikzad S, et al. Annona muricata (Annonaceae): a review of its traditional uses, isolated acetogenins and biological activities. International Journal of Molecular Sciences. 2015;16(7):15625-15658

2. Adeyemi DO, Komolafe OA, Adewole OS, et al. Anti hyperglycemic activities of Annona muricata (Linn). The African Journal of Traditional, Complementary and Alternative Medicines. 2008;6(1):62-69.

3. Adewole SO, Ojewole JAO. Protective effects of Annona muricata Linn. (Annonaceae) leaf aqueous extract on serum lipid profiles and oxidative stress in hepatocytes of streptozotocin-treated diabetic rats. African Journal of Traditional, Complementary and Alternative Medicines. 2009;6(1):30-41.

4. Baskar R, Rajeswari V, Kumar TS. In vitro antioxidant studies in leaves of Annona species. Indian Journal of Experimental Biology. 2007;45(5):480-485.

5. Osorio E, Arango GJ, Jimenez N, et al. Antiprotozoal and cytotoxic activities in vitro of Colombian Annonaceae. Journal of Ethnopharmacology. 2007;111(3):630-635.

6. Takahashi JA, Pereira CR, Pimenta LPS, et al. Antibacterial activity of eight Brazilian annonaceae plants. Natural Product Research. 2006;20(1):21-26.
7. Padma P, Chansouria JP, Khosa RL. Hepatoprotective activity of Annona muricata Linn. and Polyalthia cerasoides bed. Ancient Science of Life. 1999;19(1-2):7-10.

8. Santhoskumar M, Brindha D. Inhibitory effect of hydroethanolic extracts of Annona muricata on human platelet aggregation and hemolysis in vitro. International Journal of Pharmacy and Pharmaceutical Research. 2015;2(4):207-213.

9. Badrie N, Schauss AG. Soursop (Annona muricata L.): composition, nutritional value, medicinal uses, and toxicology. In: Watson RR, Preedy VR (eds.), Bioactive Foods in Promoting Health. Oxford; 2009. 621$643 \mathrm{p}$.

10. Neha W, Blessy BM, Suresh KJ, et al. Lipid peroxidation: Mechanism, models and significance. Int J Curr Sci. 2012;3:29-38.

11. Almeida MM, de Sousa PH, Arriaga AM, et al. Bioactive compounds and antioxidant activity of fresh exotic fruits from northeastern Brazil. Food Research International. 2011;44(7):2155-2159.

12. Correa-Gordillo J, Ortiz J, Sanchez-Mejia M, et al. Actividad antioxidante en guanabana (Annona muricata L.) una revision bibliografica. Bol Latinoam Caribe Plant Med Aromat. 2012;11(2):111-126.

13. Allisson BJ, Natália CM, Rodrigo RF, et al. Annona muricata Linn. leaf as a source of antioxidant compounds with in vitro antidiabetic and inhibitory potential against $\alpha$-amylase, $\alpha$-glucosidase, lipase, non-enzymatic glycation and lipid peroxidation. Biomedicine \& Pharmacotherapy. 2018;100:83-92.

14. Ohkawa H, Ohishi N, Yagi K. Assay for lipid peroxides in animal tissues thiobarbituric acid reaction. Analytical Biochemistry. 1979;95(2):351358

15. Halliwell B, Gutteridge JMC. Oxygen toxicity, oxygen radicals, transition metals and disease. Biochem J. 1984;219(1):1-14.

16. Halliwell B. Free Radicals in Biology and Medicine. 4th ed. Oxford, UK: Oxford University Press; 2007.

17. Halliwell B, Gutteridge JMC. Biologically relevant metal ion-dependent hydroxyl radical generation: An update. FEBS Lett. 1992;307(1):108112.

18. Halliwell B, Gutteridge JMC. Role of free radicals and catalytic metal ions in human disease: An overview. Meth Enzymol. 1990;186:1-85.

19. Wardman P, Candeias LP. Fenton chemistry: An introduction. Radiat Res. 1996;145(5):523-531.

20. Gutteridge JMC, Halliwell B. Free radicals and antioxidants in the year 2000. A historical look to the future. Ann NY Acad Sci. 2000;899:136147

21. Biemond P, Swaak AJ, van Eijk HG, et al. Superoxide dependent iron release from ferritin in inflammatory diseases. Free Radic Biol Med. 1988;4(3):185-198

22. Paul T. Effect of a prolonged superoxide flux on transferrin and ferritin. Arch Biochem Biophys. 2000;382(2):253-261.

23. Anu R, Amit K, Vivek S, et al. Oxidative Stress, Prooxidants, and Antioxidants: The Interplay. BioMed Research International. 2014;2014:761264.

24. Halliwell B. Free radicals and antioxidants-quo vadis?. Trends in Pharmacological Sciences. 2011;32(3):125-130.

25. Amber K, Shiman M, Badiavas E. The Use of Antioxidants in RadiotherapyInduced Skin Toxicity. Integrative Cancer Therapies. 2013;13(1):38-45

26. Yagi K. Simple assay for the level of total lipid peroxides in serum or plasma. Methods Mol Biol. 1998;108:101-106. 
27. Devasagayam TPA, Boloor KK, Ramasarma T. Methods for estimating lipid peroxidation: An analysis of merits and demerits. Indian Journal of Biochemistry and Biophysics. 2003;40(5):300-308.

28. Rahman K. Studies on free radicals, antioxidants, and co-factors. Clinical Interventions in Aging. 2007;2(2):219-236.

29. Poljsak B, Glavan U, Dahmane RD. Skin Cancer, Free Radicals and Antioxidants. International Journal of Cancer Prevention. 2011;4(3):1554-1134.

30. Foyer C. Redox Homeostasis and Antioxidant Signaling: A Metabolic Interface between Stress Perception and Physiological Responses. The Plant Cell Online. 2005;17(7):1866-1875.

31. Mohan S, Nandhakumar L. Role of various flavonoids: hypotheses on novel approach to treat diabetes. J Med Hypotheses Ideas. 2014;8(1):16.

32. Istasse T, Jacquet N, Berchem T, et al. Extraction of honey polyphenols: method development and evidence of cis isomerization. Anal Chem Insights. 2016;11:49-57.

33. George VC, Kumar DN, Suresh PK, et al. Antioxidant, DNA protective efficacy and HPLC analysis of Annona muricata (soursop) extracts. $J$ Food Sci. 2015;52(4):2328-2335.

34. Barchan A, Bakkali M, Arakrak A, et al. The effects of solvents polarity on the phenolic contents and antioxidant activity of three mentha species extracts. Int J Curr Microbiol Appl Sci. 2014;3(11):399-412.

35. Harris RC, Soderlund K, Hultan E. Elevation of creatine in resting and excercised subjects by creatin supplementation. Clinical Science (London). 1992;83(3):367-374.

36. Koppenol WH, Joel F, Liebman J. The oxidizing nature of the hydroxyl radical. Journal of Physical Chemistry. 1984;88(1):99-101.

37. Repetto MG, Ferrarotti NF, Boveris A. The involvement of transition metal ions on iron- dependent lipid peroxidation. Archives of Toxicology. 2010a;84(4):255-262.

38. Repetto MG, Boveris A. Transition metals: bioinorganic and redox reactions in biological systems. In: Transition metals and characteristics. Nova Science; 2012. 349-370 p.
39. Junyent F, de Lemos L, Verdaguer E, et al. Lack of Jun-N-terminal kinase 3 (JNK3) does not protect against neurodegeneration induced by 3-nitropropionic acid. Neuropathology and Applied Neurobiology. 2012;38(4):311-321.

40. Bhateja DK, Dhull DK, Gill A, et al. Peroxisome proliferator-activated receptor- $\alpha$ activation attenuates 3 -nitropropionic acid induced behavioral and biochemical alterations in rats: possible neuroprotective mechanism. Europe Journal of Pharmacology. 2011;674(1):33-43.

41. Kim JH, Kim S, Yoon IS, et al. Protective effects of ginseng saponins on 3-nitropropionic acid-induced striatal degeneration in rats. Neuropharmacology. 2005;48(5):743-756.

42. Ahmad B. Zerumbone: A natural compound with anti-cholinesterase activity. American Journal of Pharmacology and Toxicology. 2008;3(3):209-211.

43. Stone TW. Neuropharmacology of quinolinic and kynurenic acids. Pharmacology Review. 1993;45(3):309-379.

44. Reif DW, Simmons RD. Nitric oxide mediates iron release from ferritin. Arch Biochemical Biophysics. 1990;283(2):537-541.

45. Hakime HO, Ilayda SB, Temine S. Antioxidant Activity of Extracts of Soursop (Annona muricata L.) Leaves, Fruit Pulps, Peels, and Seeds. Pol J Food and Nutr Sci. 2019;69(4):359-366.

46. George VC, Kumar DR, Rajkumar V, et al. Quantitative assessment of the relative antineoplastic potential of the n-butanolic leaf extract of Annona muricata Linn. In normal and immortalized human cell lines. Asian Pac J Cancer Prev. 2012;13(2):699-704.

47. Liu P, Kallio H, Yang B. Phenolic compounds in hawthorn (Crataegus grayana) fruits and leaves and changes during fruit ripening. Journal of Agricultural and Food Chemistry. 2011;59(20):11141-11149.

48. Akomolafe SF, Ajayi OB. A comparative study on antioxidant properties, proximate and mineral compositions of the peel and pulp of ripe Annona muricata (L.) fruit. International Food Research Journal. 2015;22(6):2381-2388. 